\title{
Quality of life of Health care professionals in pandemic times
}

Jonas Jardim de Paula ${ }^{1,2}$, Danielle Souza Costa ${ }^{1}$, Alexandre Serpa ${ }^{1,3}$, Mayra Pinheiro ${ }^{1,4}$, Antonio Geraldo Silva $^{1,5}$, Leandro Malloy-Diniz ${ }^{1}$, Debora Marques de Miranda ${ }^{1}$

1 - Faculdade de Medicina, Universidade Federal de Minas Gerais, Belo Horizonte, Brazil; 2 - Faculdade de Ciências Médicas de Minas Gerais, Belo Horizonte, Brazil; 3 - Universidade Mackenzie, São Paulo, Brazil; 5 - Ministério da Saúde, Governo do Brazil, Brasília, Brazil; 6 - Associação Brasileira de Psiquiatria, São Paulo, Brazil

\section{Author Note}

We acknowledge the Brazilian Psychiatry Association and Brazilian Health Ministry which support strategies to reach the large number of health professionals nationally.

Correspondence concerning this article should be addressed to Jonas Jardim de Paula, Laboratório de Neurociência, Faculdade de Medicina da Universidade Federal de Minas Gerais; Alfredo Balena av. 190; Belo Horizonte, Brazil. Postal code 30130-100. Email: jonasjardim@gmail.com 


\begin{abstract}
The COVID-19 pandemics were an event where there was a rupture of the life pattern and people felt helpless and suffering, creating a need for basic things such as medical care and shelter against the environmental conditions. The healthcare professionals faced an unknown potential threat to life that made them work in an intense and fearful routine facing fatigue and the fear to carry the disease to their families. In order to evaluate their Quality of life, we undertook a survey in the first months of the pandemics with logistical support of the Health ministry in Brazil reaching more than 200,000 varied health professionals, with quality of life data available to 97,379 . We segregated the professionals by their reported area in Medical doctor, psychologists, social worker, nurses, pharmaceutic/biochemistry, nutritionists, physiotherapist, and speech therapists. Here we describe the findings of the reported quality of life and the features more related to the worsening of the quality of life. The different professions report a diverse quality of life, suggesting a more heterogeneous pattern of impairment. The social relations domain of quality of life was the most affected in or sample Knowing the target population and the features related to worsening of quality of life might help to prepare the professionals for what they must face and to improve mental health in this population.
\end{abstract}

Keywords: college teaching, student evaluations of teaching, online administration, response rate, assessment 


\section{Quality of life of Health care professionals in pandemic times}

COVID-19 pandemics were an event where there was a rupture of the life pattern and people felt helpless and suffering, creating a need for basic things such as medical care and shelter against the environmental conditions. Exactly as described as a natural disaster, pandemic is not classically described as a disaster, but clearly mimics one in how its disorganized society and promoted distress. It caused an increase in stress and long-term consequences (Cherry et al., 2017). Societal structure showed all the responses to a disaster, it first had a panic, a rush to the supermarkets, a closure of schools and an end of world perspective. Since the pandemic stands for longer than imagined for most there are also feelings of tiredness, powerless and exhaustion after something bad. Some increased the psychiatric symptoms and fear of being infected was spread everywhere while the pandemic disseminated and generated more affected and deaths to count. However, months later people started to adjust their behavior and expectancies, and a new routine was established. Everything started to open and the sensations of everything had gone until the next infection wave and a new movement to home and to city closure. The economic burden increases enormously, but no one could see another way to handle the whole situation.

In China when the COVID-19 first hit a country, Chinese study shows that participants felt horrified and apprehensive due to the pandemic one week after the Wuhan lockdown (Zhang et al., 2020). Family and friends devoted increased support and they shared feelings and caring for family members and others. At this point, a Chinese sample has reported no financial stress, no stress at home or at work, but even having only a week of lock down, they considered the pandemic condition as a mild stressful situation (Zhang et al., 2020). Besides their quick response, there is all the novelty and expectations about the potential of the dissemination and severity of an infectious disease. It suddenly reached the whole world distributing uncertainty to all and disrupting the perceived individual's ability to live a fulfilling life for both the risk of disease or the social distancing procedures and social isolation. 
The World Health Organization (WHO) outlines one definition of QOL; “An individual's perception of their position in life in the context of the culture in which they live and in relation to their goals, expectations, standards and concerns" (WHOQOL Group, 1995). Quality of life includes environmental, individual, and economic features. In the pandemic there is a rupture in the economic status, the social networking and a reduction in perceived social support that might change the quality of life perceptions. For patients with SARS COV-2, the psychological and physical burden result in loss of perceived QOL (Chen et al., 2020). But the perceived QOL of health professional is still undocumented.

Health professionals were in the front-line. It is important to fully understand how the pandemic impacted them even to still accounting and to prepare to stand the necessary care. One of the conditions already described to promote a better response to any disaster is the sense of preparedness. However, it is widely recognized that individual and community preparedness might mitigate hazards, since it improves the decision making through protective actions. There is no way to be prepared for a pandemic on such a scale as COVID-19 has been, however the sense of preparedness came by the interaction of some features in a complex way: having a previous experience, perceiving the risk, and feeling prepared. In Korea, recognition of emergency code recognition by nurses were positively correlated with self-confidence and disaster-related nursing competencies (Jeong \& Lee 2020). About infectious diseases, health care professionals are in frequent risk to have contact with infectious diseases. Sometimes a life-threatening disease, such as caused by the Ebola virus and it might have compromised some quality of life features resulting in an increase in the social isolation of health professionals (Lehmann et al. 2016). In the Ebola outbreak, lack of knowledge about the disease and fatigue were good predictors of the loss of quality of health (Lehmann et al. 2016).

We evaluate the QOL in a large sample of health professionals in the very beginning of a pandemic in Brazil, a country largely hit by the COVID-19. 


\section{Methods}

\section{Participants}

In this study we assessed a large sample of health Brazilian professionals enrolled in COVID-19 assessment and treatment in the early days of the pandemic ( $n=97379)$. The sample was formed by medical doctors ( $n=990)$, speech therapists $(n=507)$, physiotherapists $(n=17.436)$, psychologists ( $n=2352)$, nurses $(n=16.640)$, nurse assistants $(n=3152)$, communitarian health agents $(n=185)$, biologists $(n=2252)$. Biomedics ( $n=4360)$, physical educators (8061), biochemists/pharmaceutics $(n=3535)$, nutritionists $(n=13.680)$, dentists $(n=2343)$, social workers $(n=4.224)$, Occupational Therapists $(n=1470)$, Veterinaries/Sanitarists ( $n=7073)$ and other professionals $(n=2010)$. An additional 7490 participants with occupations non-related to healthcare were included as a control group. The sample was recruited and assessed using an online platform developed in SurveyMonkey@. Participants were assessed between March and May of 2020, when Brazil was facing the initial moments of the COVID-19 pandemic. At 31/05 we had 514.200 confirmed COVID-19 cases and 29.314 deaths, according to Brazilian health authorities (Ministério da Saúde do Brasil, 2020).

\section{Assessment of Quality of Life}

We used the WHOQOL-BREF questionnaire (WHO, 1995) to assess quality of life in our sample. The instrument involves 26 questions designed to assess four domains of aspects of this construct: physical, psychological, social, and environmental quality of life. The WHOQOL-BREF was adapted to Brazilian Portuguese by Fleck and colleagues (Fleck et al. 1999;2000), and shows robust evidence of validity and reliability in this context (Cruz et al. 2011; Chachamovich et al. 2007). Normative data was provided by Cruz and colleagues (2011) studying a sample of 751 adults aged between 20 and 64 years. WHOQOL-BREF scores were computed as recommended using the syntax available from the 
Washington University (WHOQOL Group, 1997), and transformed in a 100-points scale to perform descriptive statistics.

\section{Statistical procedures}

We used descriptive statistics to better characterize our sample. WHOQOL-BREF scores were stratified according to each professional group. Univariate analysis of variance was used to compare the different professions, using the Games-Howell post hoc test for multiple comparisons. Those procedures were performed in SPSS 25.0

Our sample size provides $>99 \%$ power to detect low, moderate of large effect sizes according to computations using the G*Power software version 3.1.9.2 (Faul, Erdfelder, Lang \& Buchner, 2003). However, due to multiple comparisons, we adopted more conservative significance values at (0.01), despite the post hoc test and the large sample size.

\section{Results}

Participants description is shown on Table 1. Most of our sample was formed by middle-aged (61\%) women (80\%). At the time $4 \%$ of our sample was tested for COVID-19 and $1 \%$ were positive. Participants showed a history of mental disorders (23\%), direct work with COVID-19 diagnosis and treatment (2\%) and current economical struggle (36\%) or the fear of it (47\%), suggesting an environmental context marked by negative stress.

----INSERT TABLE 1 ABOUT HERE ----

The results from the WHOQOL-BREF are shown in Table 2. We added the normative values from the full sample of Cruz and colleagues' study (2011) as reference. Comparing the normative data 
with our current sample we saw an increased physical (58.90 to 59.57$)$ but lower social relations (76.20 to 62.92) quality of life, without large differences in psychological and environmental quality of life (lesser than 2 points in each).

---- INSERT TABLE 2 ABOUT HERE ----

A comparison between different professions showed a more heterogeneous pattern of differences (Figure 1). The highest quality of life scores for most professionals was in the physical domain, followed by psychological, social relations and environmental domains. Higher environmental than social quality of life was seen in Medical doctors, and similar values between those two domains were seen in Occupational Therapists and Veterinarians. Post hoc comparison revealed an overall similar pattern. Most significant differences were seen in the physical domain, while fewer differences were seen in the social relations.

\section{Discussion}

QOL is a wide concept representing a state consisting of experiences, capacities, relationships, and reactions in a specific circumstance. The four domain of the instrument represent well information about physical information (e.g. sleep, energy and pain), psychological (e.g. Feelings, body image and self-esteem), social relationships (e.g. Personal and social support), and environment (e.g. Home, safety, leisure) (Skevington et al., 2004). We can see an interesting picture of much happening with the studied population. We choose to measure the QOL using the WHOQOL-BREF, since it seems to have good psychometric properties and reliability, being also an integrated instrument and well validated but not exhaustive to fill in epidemiological surveys (Skevington et al., 2004) and contemplating these different biopsychosocial domains. 
Overall, at the beginning of the pandemic, all health professions answer relatively well to the instability and uncertainty of its effects in daily life, with higher scores in the physical domain and similar scores in psychological and environmental domains. However, already in these first months, scores in the social relationship domain were significantly lower than the parameters in normative data. This might be related to the initial emphasis in social distancing adopted in the early stages of the pandemic, which may have hindered social contact and therefore the social domain of quality of life, but worked reasonably well to maintain or improve the physical aspects of it. The social relations domain of quality of life is usually the higher score in Brazilian studies (Cruz et al., 2011; Almeida-Brasil et al., 2017), and its lower values may reflect some of the negative consequences of fighting COVID-19. Besides the initial financial impact of COVID-19 in Brazilian familiar incomed, those with a college or higher degree (all samples besides community health agents, nurse assistants and other non-listed health related professions) showed overall similar values. Medical doctors showed the higher scores in this domain, reflecting the overall higher salary of this profession compared to the other ones.

Regarding specific professions we observed a more heterogeneous pattern of QOL worsening in according to each profession. If we consider an overall mean of WHOQOL-Bref scales, there was a difference of 5 points between those who reported the highest reported QOL (professionals of Psychology and Physical Education, mean score 67) with the lowest (professionals of Nutrition, 62). Medical doctors, nurses, physiotherapists - maybe the professionals more directly involved in fighting COVID-19 showed a somewhat average score (64). When we analyze specific QOL domains, the highest differences in Physical was observed between professionals of Physical Education (74) and Occupational Therapy (68); in the psychological domain between professionals of Psychology (70) and nutrition (68); in the social relations domain between professionals of Physical Education (65) and Medicine or Veterinary (60); and lastly In the environmental domain between professionals of Medicine (63) and nurse assistants (53). 
Those differences seem related to the particular characteristics of each profession (such as the physical involvement in work practice seen in Physical Education or the mental health constant care of Psychology) or average income (in Brazil, the monthly income of medical doctors are about 7 times higher than nurse assistants). The lower scores in social QOL might be a direct effect of the pandemic and the means of fighting it, including social distancing. Changes in the social relationships and social support networks are usually related to this aspect of QOL (Helgeson, 2003; Wedgeworth et al., 2017; Zhang \& Xiang, 2019) Altogether, those factors represent different aspects of biopsychosocial functioning, including the general health status, familiar and social relationships, as well satisfaction with life and work practice, which are the main predictors of QOL (Rapala et al., 2005). Nonetheless other factors such as the presence of chronic disease and mental disorders may also affect QOL (Lewko et al, 2019).

Related to COVID-19 pandemic in Portugal, healthcare professionals had the perception of being at higher risk than the general population to be infected by SARS-COV-2, because of the close contact with potential infected cases and also because of they consider the health system was poorly prepared to contain the pandemic (Peres et al. 2020). Besides the risk, the QOL among healthcare professions was quite stable among professions. The purposeful activities might be a reason to preserve the QOL. In a previous study evaluating the doctors, the WHOQOL-BREF was associated with professional fulfillment and a sense of purpose (Trockel et al., 2018), which might help to understand the preservation of wellbeing.

The knowledge of features impacting quality of life in health professionals and the handling of these conditions is undoubtedly important to improve those interventions aiming to decrease the work stress, to avoid fatigue related to the health profession and to improve the care and safety of patients.

\section{Conclusion}


Quality of life measures a state representing psychological, social, physical and environment conditions. Health professionals have a purposeful activity and in the beginning of the pandemic they different health professions present a constant quality of life among them, except by the social aspects which seem compromised in physicians. The environment condition which is worse in some health professions might not reflect a change related to the pandemic, but a finding related with wage of certain professions.

\section{Conflict of interest}

None 


\section{References}

Almeida-Brasil, C. C., Silveira, M. R., Silva, K. R., Lima, M. G., Faria, C. D. C. D. M., Cardoso, C. L., ... \& Ceccato, M. D. G. B. (2017). Quality of life and associated characteristics: application of WHOQOL-BREF in the context of Primary Health Care. Ciência \& Saúde Coletiva, 22, 1705-1716.

Chachamovich, E., Fleck, M. P., Trentini, C., \& Power, M. (2008). Brazilian WHOQOL-OLD Module version: a Rasch analysis of a new instrument. Revista de Saúde Pública, 42, 308-316.

Chen, K. Y., Li, T., Gong, F., Zhang, J. S., \& Li, X. K. (2020). Predictors of health-related quality of life and influencing factors for COVID-19 patients, a follow-up at one month. Frontiers in Psychiatry, 11, 668.

Cherry, K. E., Sampson, L., Galea, S., Marks, L. D., Baudoin, K. H., Nezat, P. F., \& Stanko, K. E. (2017). Health-related quality of life in older coastal residents after multiple disasters. Disaster medicine and public health preparedness, 11(1), 90-96.

Cruz, L. N., Polanczyk, C. A., Camey, S. A., Hoffmann, J. F., \& Fleck, M. P. (2011). Quality of life in Brazil: normative values for the Whoqol-bref in a southern general population sample. Quality of life research, 20(7), 1123-1129.

Faul, F., Erdfelder, E., Lang, A.-G., \& Buchner, A. (2007). G*Power 3: A flexible statistical power analysis program for the social, behavioral, and biomedical sciences. Behavior Research Methods, 39, $175-191$

Fleck, M., Lousada, S., Xavier, M., Chachamovich, E., Vieira, G., Santos, L., \& Pinzon, V. (1999). Application of the portuguese version of the instrument for the assessment of the quality of life of the World Health Organization (WHOQOL-100). Revista de saude publica, 33(2), 198-205.

Fleck, M., Louzada, S., Xavier, M., Chachamovich, E., Vieira, G., Santos, L., \& Pinzon, V. (2000). Application of the Portuguese version of the abbreviated instrument of quality life WHOQOLbref. Revista de saude publica, 34(2), 178-183. 
Helgeson, V. S. (2003). Social support and quality of life. Quality of life research, 12(1), 25-31.

Jeong, S., \& Lee, O. (2020). Correlations between emergency code awareness and disaster nursing competencies among clinical nurses: A cross-sectional study. Journal of nursing management, 10.1111/jonm.13086. Advance online publication. https://doi.org/10.1111/jonm.13086

Lehmann, M., Bruenahl, C. A., Addo, M. M., Becker, S., Schmiedel, S., Lohse, A. W., ... \& Löwe, B. (2016). Acute Ebola virus disease patient treatment and health-related quality of life in health care professionals: A controlled study. Journal of psychosomatic research, 83, 69-74.

Lewko, J., Misiak, B., \& Sierżantowicz, R. (2019). The relationship between mental health and the quality of life of Polish nurses with many years of experience in the profession: a cross-sectional study. International journal of environmental research and public health, 16(10), 1798.

Ministério da Saúde do Brasil (2020). Painel Coronavírus. Available at https://covid.saude.gov.br/

Rapała, A., \& Jasiński, T. (2005). Quality of life of physicians and their patients. Ortopedia, traumatologia, rehabilitacja, 7(1), 87-91.

Peres D., Monteiro J., Almeida M.A., and Ladeira R. Risk perception of COVID-19 among Portuguese healthcare professionals and the general population. Journal of Hospital Infection, 105(3):434437, 2020.

Skevington, S. M., Lotfy, M., \& O'Connell, K. A. (2004). The World Health Organization's WHOQOL-BREF quality of life assessment: psychometric properties and results of the international field trial. A report from the WHOQOL group. Quality of life Research, 13(2), 299-310.

Wedgeworth, M., LaRocca, M. A., Chaplin, W. F., \& Scogin, F. (2017). The role of interpersonal sensitivity, social support, and quality of life in rural older adults. Geriatric Nursing, 38(1), 22-26.

WHOQOL Group (1997). Syntax file to score the WHOQOL-BREF. Available at http://depts.washington.edu/seaqol/docs/Wq_bref.txt. 
Whoqol Group. (1995). The World Health Organization quality of life assessment (WHOQOL): position paper from the World Health Organization. Social science \& medicine, 41(10), 1403-1409.

Trockel, M., Bohman, B., Lesure, E., Hamidi, M. S., Welle, D., Roberts, L., \& Shanafelt, T. (2018). A brief instrument to assess both burnout and professional fulfillment in physicians: reliability and validity, including correlation with self-reported medical errors, in a sample of resident and practicing physicians. Academic Psychiatry, 42(1), 11-24.

Zhang, S., \& Xiang, W. (2019). Income gradient in health-related quality of life-the role of social networking time. International journal for equity in health, 18(1), 1-10.

Zhang, Y., \& Ma, Z. F. (2020). Impact of the COVID-19 pandemic on mental health and quality of life among local residents in Liaoning Province, China: A cross-sectional study. International journal of environmental research and public health, 17(7), 2381. 


\section{Table 1}

Participant's description

\begin{tabular}{|c|c|c|c|}
\hline & & $\mathrm{N}$ & $\%$ \\
\hline \multirow[t]{2}{*}{ Sex } & Male & 19166 & $20 \%$ \\
\hline & Female & 78213 & $80 \%$ \\
\hline \multirow[t]{3}{*}{ Age } & $<30$ years & 30270 & $31 \%$ \\
\hline & $30-50$ years & 57259 & $61 \%$ \\
\hline & $>50$ years & 7850 & $8 \%$ \\
\hline \multirow[t]{18}{*}{ Occupation } & Non-Health related profession & 7490 & $8 \%$ \\
\hline & Community Health Agent & 185 & $0 \%$ \\
\hline & Nurse Assistant & 3152 & $3 \%$ \\
\hline & Biology & 2254 & $2 \%$ \\
\hline & Biomedicine & 4369 & $5 \%$ \\
\hline & Physical Education & 8061 & $8 \%$ \\
\hline & Nurse & 16640 & $17 \%$ \\
\hline & Pharmaceutical Science & 3535 & $4 \%$ \\
\hline & Physical Therapy & 17436 & $18 \%$ \\
\hline & Speech Therapy & 507 & $1 \%$ \\
\hline & Medicine & 990 & $1 \%$ \\
\hline & Nutrition & 13680 & $14 \%$ \\
\hline & Dentistry & 2343 & $2 \%$ \\
\hline & Psychology & 2352 & $2 \%$ \\
\hline & Social Worker & 4224 & $4 \%$ \\
\hline & Occupational Therapist & 1470 & $2 \%$ \\
\hline & Veterinary & 7073 & $7 \%$ \\
\hline & Other & 2010 & $2 \%$ \\
\hline \multirow[t]{2}{*}{ History of mental disorder } & No & 74750 & $77 \%$ \\
\hline & Yes & 22862 & $23 \%$ \\
\hline \multirow[t]{2}{*}{ Tested for COVID-19 } & No & 93972 & $96 \%$ \\
\hline & Yes & 3799 & $4 \%$ \\
\hline \multirow[t]{2}{*}{ Positive Testing for COVID-19 } & No & 96623 & $99 \%$ \\
\hline & Yes & 1148 & $1 \%$ \\
\hline \multirow[t]{2}{*}{ Direct work with COVID-19 } & No & 95544 & $98 \%$ \\
\hline & Yes & 2227 & $2 \%$ \\
\hline \multirow[t]{2}{*}{ Economic Struggle (current) } & No & 62827 & $64 \%$ \\
\hline & Yes & 34944 & $36 \%$ \\
\hline \multirow[t]{2}{*}{ Fear of economic Struggle (future) } & No & 51492 & $53 \%$ \\
\hline & Yes & 46279 & $47 \%$ \\
\hline
\end{tabular}


Table 2

Quality of life in different health professions

Quality of Life (WHOQOL-BREF scores) ${ }^{1}$

\begin{tabular}{|c|c|c|c|c|c|c|c|c|}
\hline & \multicolumn{2}{|c|}{ Physical } & \multicolumn{2}{|c|}{ Psychological } & \multicolumn{2}{|c|}{ Social Relations } & \multicolumn{2}{|c|}{ Environment } \\
\hline & M & SD & M & SD & M & $\mathrm{SD}$ & M & SD \\
\hline Normative data ${ }^{2}$ & 58.90 & 10.50 & 65.90 & 10.80 & 76.20 & 18.80 & 59.90 & 14.90 \\
\hline Non-Health related profession & 72.04 & 16.83 & 67.87 & 17.70 & 63.41 & 20.81 & 60.25 & 15.78 \\
\hline Communitary Health Agent & 68.29 & 16.97 & 66.03 & 18.11 & 63.49 & 20.51 & 54.29 & 16.49 \\
\hline Nurse Assistant & 70.61 & 17.48 & 66.84 & 18.67 & 62.90 & 21.91 & 52.54 & 16.39 \\
\hline Biology & 69.33 & 16.84 & 64.99 & 18.05 & 62.02 & 20.67 & 59.60 & 15.76 \\
\hline Biomedicine & 69.70 & 16.18 & 63.64 & 18.07 & 61.97 & 20.83 & 58.02 & 14.94 \\
\hline Physical Education & 73.67 & 16.29 & 69.28 & 17.41 & 64.62 & 20.41 & 61.13 & 15.21 \\
\hline Nurse & 70.14 & 16.93 & 65.10 & 18.04 & 61.74 & 21.11 & 57.41 & 15.52 \\
\hline Pharmaceutical Science & 71.80 & 16.51 & 66.32 & 17.60 & 62.15 & 21.22 & 56.92 & 15.81 \\
\hline Physical Therapy & 70.24 & 16.01 & 63.71 & 17.44 & 61.95 & 20.27 & 59.24 & 14.97 \\
\hline Speech Therapy & 68.62 & 16.37 & 64.19 & 16.73 & 60.63 & 20.18 & 59.29 & 14.68 \\
\hline Medicine & 69.90 & 16.34 & 64.30 & 17.89 & 60.31 & 21.48 & 62.68 & 15.54 \\
\hline Nutrition & 68.46 & 16.16 & 62.13 & 17.34 & 60.69 & 20.47 & 58.29 & 15.29 \\
\hline Dentistry & 68.91 & 17.41 & 64.57 & 18.06 & 61.16 & 21.91 & 59.35 & 15.70 \\
\hline Psychology & 72.21 & 15.45 & 69.87 & 15.58 & 64.17 & 19.80 & 61.12 & 14.53 \\
\hline Social Work & 71.03 & 16.60 & 68.20 & 16.96 & 64.06 & 20.35 & 57.81 & 14.93 \\
\hline Occupational Therapy & 67.63 & 15.80 & 62.67 & 16.30 & 60.91 & 19.47 & 60.76 & 14.05 \\
\hline Veterinary & 69.17 & 16.62 & 62.79 & 18.45 & 59.80 & 20.92 & 59.90 & 15.15 \\
\hline Other & 71.33 & 17.28 & 66.87 & 18.08 & 63.47 & 21.71 & 54.91 & 16.07 \\
\hline
\end{tabular}

1 - Higher scores indicate higher quality of life

2 - Based on Cruz and colleagues (2011) normative values for the Brazilian population 


\section{Figure 1}

Quality of life (WHOQOL scores) in different health professions

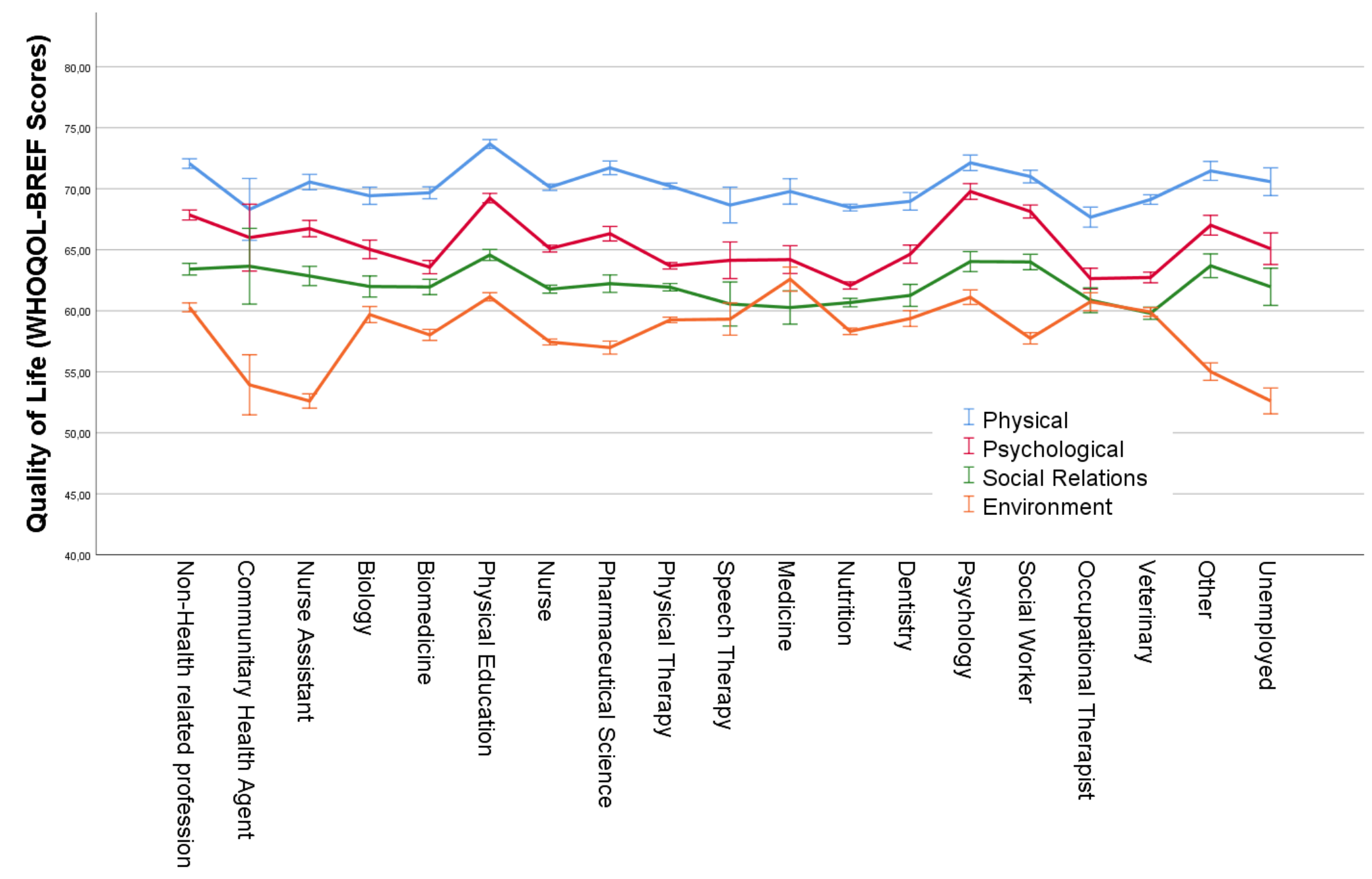

